\title{
Micro-história, macro-história: o que as variações de escala ajudam a pensar em um mundo globalizado
}

Jacques Revel

École des Hautes Études en Sciences Sociales, Paris

Tradução de Anne-Marie Milon de Oliveira

Revisão técnica de José G. Gondra
Desde os anos de 1980, levar em consideração as escalas de observação assumiu um lugar importante no debate dos historiadores. O programa de uma microhistória foi recebido como uma proposta nova, incômoda, nem que fosse porque rompia com os hábitos da historiografia dominante. Ele suscitou com certeza mais espanto do que convicção, foi frequentemente acolhido com incompreensões e encontrou, reconheçamos, mais que reticência por parte dos historiadores profissionais.

No decorrer dos anos de 1990, como que num efeito de balanço, a área de história global pareceu voltar ao primeiro plano, com uma diversidade de proposições cujos títulos podiam ser diferentes (World History, Global History, Connected Histories, histoires croisées, até uma Big History), cujos pressupostos metodológicos e programas não correspondiam exatamente entre si, mas que tinham em comum o fato de reivindicar a necessidade de levar em conta os fenômenos maciços, as longas durações, os espaços vastos. É oportuno lembrar que o XIX Congresso de Ciências Históricas, realizado em Oslo em 2000, proclamava como seu primeiro tema de reflexão: "Perspectives on Global
History: Concepts and Methodology" (Perspectivas sobre a História Global: Conceitos e Metodologia).

Com toda certeza, seria por demais simples - e simplificador - não ver nada nisso além dos efeitos de uma moda e uma série de oscilações em volta do que poderia ser um ponto de equilíbrio por demais ilusório. A tese que gostaria de defender aqui e que procurarei ilustrar é que essas proposições, muitas vezes percebidas e apresentadas como alternativas, remetem, todas elas, a um certo número de interrogações sobre a natureza e o funcionamento daqueles objetos sociais que escolhemos estudar.

Antes de chegar a isso, desejo, entretanto, relembrar que nem tudo é inédito nos debates que ocupam os historiadores hoje. Faz agora sessenta anos que Fernand Braudel defendia sua tese, A Mediterrânea e o mundo mediterrâneo na época de Felipe II, publicada dois anos mais tarde, em 1949, na sua primeira versão (Braudel, 1966). Na época, o livro fora recebido - e ainda o é hoje amplamente - como um manifesto em favor de uma história decidida a não fixar outros limites a não ser aqueles requeridos pela compreensão do assunto, qualquer que seja o quadro 
geográfico e cronológico anunciado no título. Assim, para as necessidades da análise, o Mediterrâneo de Braudel é suscetível de dilatar-se até a África das savanas nos primeiros tempos da colonização e até a Ásia central. Desse modo, os dados recolhidos para a segunda metade do século XVI podem ser recolocados e reinterpretados numa muito longa duração. Sobretudo na primeira parte da obra, que trata das relações entre as sociedades humanas e o meio natural, essa duração é a das implantações humanas no mundo mediterrâneo, ou seja, uma profundidade de vários milênios. O livro de Braudel foi amplamente discutido, ainda que não tenha engendrado uma real posterioridade historiográfica perante o tamanho de suas ambições - provavelmente em razão do caráter intimidante dessas ambições.

Além disso, devido em particular à insistência na "longa duração" que era, quero lembrar, o título de um artigo de Braudel, publicado em 1958, podemos pensar que a obra desse autor é uma das que colocou explicitamente no centro da reflexão dos historiadores uma preocupação: a de apreender as realidades sócio-históricas dentro de quadros analíticos que as ultrapassam amplamente e dos quais se esperava que fossem capazes de restituir a mais justa perspectiva.

O mesmo pode ser dito da micro-história. Uma das primeiras obras que reivindicou pertencer a esse gênero, e do qual poderíamos até dizer que é inventora, foi o livro de um historiador mexicano, Luís González y Gonzáles, Pueblo en vilo: microhistoria de San José de Gracia, publicado em 1968. ${ }^{1}$ Tratava-se de um estudo monográfico sobre uma comunidade aldeana do México central ao longo de quatro séculos, levado a cabo com a convicção de que esse tipo de abordagem seria suscetível de restituir uma parte ignorada ou escondida da existência social, uma parte que o autor não hesitava em caracterizar como mátria, feminina, próxima, familiar, afetiva. ${ }^{2}$ A monografia e, particular-

${ }^{1}$ Um inventário das primeiras ocorrências de micro-história encontra-se num artigo de Carlo Ginzburg (1994).

${ }^{2}$ L. González desenvolveu depois sua concepção da microhistória numa série de obras posteriores à sua monografia de San mente, a monografia aldeana é um gênero solidamente instalado nos hábitos historiográficos e González não é, com certeza, seu inventor. Mas o que me parece interessante nele é a ideia de que uma outra história é possível a partir da escolha de um ponto de vista particular. Pouco importa, no limite, que fiquemos ou não convencidos pelas razões invocadas pelo historiador mexicano ou pelo seu projeto de reencontrar, no quadro da comunidade de residência, o elemento "feminino, conservador, terrestre, doce, obscuro e doloroso" da vida social. Não temos nenhuma obrigação de assumir esses termos. O que pode, em contrapartida, reter nossa atenção, é o laço estabelecido entre o quadro analítico e as realidades das quais ele pretende dar conta.

Estes apontamentos, entre outros possíveis, não têm por objetivo sugerir que tudo já foi dito, que a reflexão historiográfica não faz nada a não ser percorrer de novo, de forma cíclica, suas próprias trilhas após tê-las provavelmente esquecido. Tampouco procuram legitimar uma espécie de decisão metodológica soberana, de forma que a escolha de um partido desqualificaria imediatamente qualquer outra escolha possível. Braudel indubitavelmente tinha pouca estima pela micro-história que ele identificava prontamente com a "pequena história" ou ainda com a história fatual dos historiadores tradicionais (Braudel, 1969, p. 112). Com certeza González estava à procura de um meio de escrever uma outra história, em contraponto às grandes narrativas da história nacional ou das lutas políticas que comandaram e comandam ainda a construção do passado mexicano. Certamente tinha consciência deste fato essencial já lembrado com tanta ênfase por Arnaldo Momigliano (1983): fazer a escolha de uma história particular significa, de fato, eliminar - ou, pelo menos, suspender por hipótese - uma pluralidade de outras histórias possíveis. Mas tais decisões não são nem clandestinas nem arbitrárias. Elas são, na maioria dos casos, explicitadas, o que é positivo para a saúde intelectual da nossa profissão. Afinal de contas, ao longo de toda sua vida de historiador, Braudel nunca

José de Gracia: Invitación a la microhistoria (1973), seguida por Nueva invitacion a la microhistoria (1982). 
deixou de argumentar as razões das suas escolhas historiográficas e de explicar os benefícios que ele esperava da abordagem pela longa duração e pelos vastos espaços, em termos de conhecimento. Ela justificava, a seus olhos, que se recusasse o evento, como se faz num estudo de caso, entre outros "sacrifícios necessários", devido ao que ele julgava ser seu escasso valor explicativo. Essas razões e explicações podem convencer-nos ou não, o que equivale a dizer que elas são sujeitas à discussão e à contradição.

Não se esperou, portanto, a última geração de historiadores para opor, e às vezes com uma nitidez notável, as abordagens macro e micro dos fenômenos sociais, qualquer que fosse o título que lhes desse. $\mathrm{O}$ que mudou, então, com relação a essas primeiras formulações? Parece-me que foi o seguinte: mais do que de escalas, reivindicadas como mais ou menos pertinentes, é do princípio da variação de escala que se esperam hoje benefícios heurísticos.

Tal não foi sempre o caso. Em La Méditerranée, todos lembrarão, Braudel apresentava os três andares de uma arquitetura destinada a dar conta das temporalidades diferentes da experiência social. Ele o fazia com uma consciência clara de que estava simplificando o problema da pluralidade do tempo social: "Entendamos bem: não existe tempo social correndo de uma maneira única e simples, e sim um tempo social com mil velocidades, mil lentidões e que não guardam quase nenhuma relação com o tempo jornalístico da crônica e da história tradicional". Ele colocava como um princípio também a interdependência dos tempos sociais que não cessam de reagir uns aos outros. Resta que todo privilégio estava ligado, para ele, às mais longas e mais lentas evoluções: "Creio [...] à realidade de uma história particularmente lenta das civilizações, nas suas profundidades abissais, nos seus traços estruturais e geográficos" (Braudel, 1969, p. 24). Mais ainda: "Todos os andares, todos os milhares de andares, todos os esfacelamentos do tempo da história são entendidos a partir desta profundidade, desta semi-imobilidade; tudo gravita em sua volta" (Braudel, 1958, p. 54). Efetivamente, na majestosa construção da Méditerranée, quem não vê que a primeira parte serve para compreender as duas outras e não o inverso?

Mas não é só isso. Para uma ampla parte da historiografia da segunda metade do século $\mathrm{XX}$, o modelo dominante foi o de uma história dos objetos sociais fundada na série e na medida, quer se trate de fatos econômicos, sociais ou, em último lugar, culturais. Os Annales, a revista fundada por Marc Bloch e Lucien Febvre em 1929 e depois dirigida durante muito tempo por Fernand Braudel, foi um dos locais onde desabrochou com mais força esse modelo historiográfico. Ora, essa referência francesa está longe de ser isolada: cedo ou tarde, sob formas que puderam em contrapartida ser substancialmente diferentes entre si, a maior parte das historiografias nacionais foi afetada por esse movimento de fundo. Essa orientação não encontra hoje o mesmo sucesso que nos anos de 1959-1970. É preciso lembrá-lo, ainda mais porque devemos a ela uma boa parte dos nossos conhecimentos científicos.

No caso francês, tive frequentemente a ocasião de lembrar o que ela devia à sociologia durkheimiana e à adaptação para o caso da história das suas "regras do método sociológico": os historiadores tinham-se deixado fascinar durante muito tempo pelo único, o acidental (o indivíduo, o evento, o caso singular), mas eram a partir de então convidados a se concentrar naquilo que, aos olhos dos sociólogos, só podia ser objeto de um estudo rigoroso: a observação dos "fatos que se repetem", das regularidades mediante as quais deveria ser possível estudar variações, correlações e, a partir de um certo momento, induzir leis (Simiand, 1903; Labrousse, 1933; Furet, 1971). Essa escolha epistemológica, que tinha por ambição conformar a agenda da história (e, de forma mais ampla, a das ciências sociais) à das ciências da natureza, é, sem nenhuma dúvida, o que ajuda a compreender alguns dos caracteres originais da história social na sua versão francesa - mas esta constatação pode ser, mais uma vez, generalizada. Para que a medida dos dados sóciohistóricos fosse possível e para que fosse significativa, convinha orientá-la para os agregados mais amplos e mais representativos da realidade estudada. Tal é a razão (na medida em que as fontes o permitiam) do 
estudo sistemático de amplas bases de dados, tornando possível uma amostragem racionalizada e da escolha de durações bastante longas para tornar possível a análise das transformações parciais ou globais (tendo como corolário a análise das temporalidades diferenciais). Começou-se pelo estudo das variações no tempo dos preços e rendas, depois das distribuições econômicas, sociais, profissionais. A partir dos anos de 1950, a demografia histórica foi, por excelência, uma história serial e quantitativa. Finalmente, a partir dos anos de 1960, com maior ou menor êxito, foram os dados culturais que foram submetidos a um tratamento deste tipo: começou-se a constituir, então, uma série de indícios que permitiam medir os progressos e as formas da alfabetização (a partir das assinaturas em atas cartoriais), do consumo cultural (a partir da análise da produção de livros ou de inventários de bibliotecas), da evolução das práticas de devoção ou das atitudes diante da morte etc.

A maior parte desses trabalhos foi realizada no quadro de monografias: uma aldeia, uma cidade, uma província, um grupo social - nem que fosse porque esse quadro é o que convém melhor aos exercícios de pesquisa universitária e também o que permite ao historiador dominar com mais criticidade suas fontes documentais. Entretanto, esses estudos não davam importância peculiar às dimensões do quadro monográfico e menos ainda aos efeitos de conhecimento que podiam ser-lhe associados. Isso se deve ao fato de que cada uma dessas contribuições monográficas tinha por vocação integrar um conjunto, como um tijolo numa parede. O que pode ser dito de outra forma, sugerindo que essas contribuições faziam tacitamente parte de uma perspectiva macro-histórica que seus autores não sentiam necessidade de explicitar. Uma prova evidente disso pode ser encontrada na forma como foram concebidas as grandes obras de síntese que apresentaram, de certa forma, o balanço dos conhecimentos adquiridos durante trinta anos. Para citar apenas um exemplo, a História econômica e social da França, coleção reunindo vários volumes dirigida nos anos 1960-1970 pelos dois maiores historiadores cujos nomes podem servir de emblema àquele momento da pesquisa: Ernest Labrousse e Fernand Braudel, é baseada na integração de centenas de monografias de todos os tamanhos, sem que em nenhum momento tenha sido realmente colocado o problema de saber se os dados coletados no nível local guardavam significação constante quando reutilizados em quadros mais amplos, como se, precisamente, esses quadros fossem indiferentes ou neutros.

É verdade que, em si mesmas, essas monografias eram na maioria das vezes construídas com base em um questionário geral. O problema colocado por cada uma delas não era o de uma escala de observação e dos seus possíveis efeitos, mas o da representatividade que podia ser reconhecida a cada amostragem em particular com relação ao conjunto do qual se destinava a fazer parte. Colocar o problema nesses termos significava evidentemente antecipar a existência de um valor central de referência, uma média que seja, ou um modo estatístico ou ainda um tipo perante o qual seria possível medir variações ou desvios, assim como dar conta deles. Os primeiros trabalhos de demografia histórica oferecem outro bom exemplo disso. Centrados na análise do jogo de quatro variáveis principais: natalidade, mortalidade, nupcialidade e fecundidade, eles tiveram muito cedo a ambição de definir evoluções a partir dos valores médios de cada uma delas e de dar conta da elasticidade de um modelo demográfico. Com base em amplos inquéritos nacionais e internacionais, tornou-se, assim, possível caracterizar globalmente um "Antigo Regime demográfico" e a seguir a transição que fixou as condições de uma passagem para um novo regime.

Não caberia aqui criticar esse modo de agir. Além de responder muito exatamente àquilo que se esperava dele - produzir indícios sócio-históricos globais -, ele foi, repito, de uma eficácia notável e lhe devemos ainda hoje o essencial dos nossos conhecimentos no que se refere à história das sociedades entre o fim da Idade Média e o século XX. Mas esse modelo de análise começou também então a ser questionado pelas abordagens que podemos qualificar de alternativas. Estas têm, ainda hoje, uma importância limitada, talvez marginal, com relação ao trend dominante dos estudos históricos. Mas têm o mérito de apresentar um 
elenco de questões novas e de nos convidar a revisitar nossas certezas.

Um dos méritos da micro-história é ter colocado, de saída, o problema da variação de escala e dos efeitos cognitivos que podem ser-lhe associados. É importante entender bem sua significação e o que está em jogo com isso. Ao contrário do que frequentemente se disse, a questão fundamental não é aqui a do estudo dos objetos de tamanho reduzido. A esse respeito, a abordagem micro-histórica não poderia ser identificada com a monografia ou com a perspectiva da história local. Acabei de lembrar que o regime monográfico fora plenamente compatível com um projeto macro-histórico. Não, o que está em jogo na abordagem micro-histórica é a conviç̧ão de que a escolha de uma escala peculiar de observação fica associada a efeitos de conhecimentos específicos e que tal escolha pode ser posta a serviço de estratégias de conhecimento. Retomando uma metáfora que foi muito utilizada nos últimos anos, variar a focalização de um objeto não é unicamente aumentar ou diminuir seu tamanho no visor, e sim modificar sua forma e sua trama. Ou então, para lançar mão de outro sistema de referência que a mim pessoalmente me parece mais elucidativo - o cartográfico -, a escolha de uma ou outra escala de representação não equivale a representar em tamanhos diversos uma realidade constante, e sim a transformar o conteúdo da representação mediante a escolha do que é representável.

É presido salientar - o que terei a oportunidade de tratar melhor mais adiante - que a escala micro não goza, a este respeito, de nenhum privilégio particular. É o princípio da variação de escala que importa, e não a escolha de uma escala peculiar de observação. Se a proposta micro-histórica ficou tão em evidência de uns vinte anos para cá, é antes de tudo porque, junto com outras (penso na Alltagsgeschichte na Alemanha e, num grau menor, na History Workshops na Inglaterra), ela se distanciou explicitamente do modelo dominante e pôde, ao mesmo tempo, tornar visíveis as convenções tácitas que estavam na base desse modelo. De certa forma, ela permitiu colocar o problema que nos mobiliza aqui. Ela convidou-nos a efetuar uma volta crítica aos procedimentos e instrumentos da análise histórica que nos eram mais familiares - tão familiares que nos pareciam evidentes.

$\mathrm{O}$ que se procura obter quando se faz a escolha de uma escala micro? Nos raros textos programáticos produzidos pelos micro-historiadores italianos, Edoardo Grendi (1977) observa que, por ter escolhido constituir seus dados mediante a utilização de categorias que permitam sua máxima agregação - portanto, das categorias mais gerais -, a história dominante tinha se mostrado incapaz de apreender tudo que se referia à experiência social, ou, como ele dizia em uma palavra passível de ser discutida, à "vivência" (encontramos aqui uma tonalidade que não é tão afastada daquela da micro-historia de Luís González). Reduzir o campo da análise significava, para Grendi, dar os meios de colocar em relação e, como esperava, de integrar as diferentes dimensões dessa experiência social. Não é de surpreender que, ao chegar a este ponto, Grendi tenha se referido explicitamente à abordagem antropológica (e, mais precisamente, aos modelos apresentados pela antropologia anglo-saxônica), cujos mérito e originalidade não provêm tanto, aos seus olhos, de uma metodologia específica e sim do "acento significativo que ela coloca na abordagem holística dos comportamentos". O que ele recomendava no caso era, portanto, desenvolver uma estratégia de pesquisa que não ambicionasse tanto dar conta do mundo sóciohistórico mediante um conjunto de indícios especiais e sim compreender seus funcionamentos mediante a identificação e integração do maior número possível de variáveis. É na mesma direção que iriam, alguns anos mais tarde, Carlo Ginzburg e Carlo Poni (1979) ao propor que se faça do "nome" próprio o fio condutor de uma história social diferente: o nome, ou seja, o marcador mais individual, o menos generalizável de todos (em oposição a categorias gerais tais como o nível de renda ou de fortuna, o estatuto socioprofissional etc.). É claro que havia uma vontade de provocação em tal proposta. Mas é também possível ler nela o esboço de outra modalidade de análise social, própria de uma história que almejasse atentar para a experiência dos indivíduos captada nas relações que eles mantêm com outros indivíduos. A escolha do individual não era 
considerada, no caso, contraditória com a apreensão do social: o que se esperava dela era que tornasse possível a inclusão de uma trajetória individual (a de um homem ou de um grupo de homens) numa multiplicidade de espaços e de tempos sociais, pelo novelo de relações sociais que se criam em volta dessa trajetória e dão-lhe sua significação: "se o terreno da pesquisa for suficientemente circunscrito, as séries documentais particulares podem ser superpostas na duração assim como no espaço, o que permite reencontrar o mesmo indivíduo em contextos sociais diferentes" (Ginzburg \& Poni, 1979).

As ilustrações empíricas mostraram a possível riqueza desse programa definido de forma muito e talvez exageradamente ampla mediante uma série de trabalhos sobre os quais não tenho agora o tempo de me demorar. Quer se trate da explicitação de um caso excepcional como o de Mennochio, o moleiro heterodoxo do livro de Ginzburg, O queijo e os vermes (Turim, 1976); quer seja da análise de lógicas de agregação social a partir de trajetórias individuais socializadas como as que Simona Cerutti reconstituiu a propósito das corporações turinenses nos séculos XVII e XVIII (La Ville et les Métiers, Paris, 1991); ou da análise de fenômenos de mobilidade social como aqueles que $\mathrm{M}$. Gribaudi estudou nos mecanismos de formação de uma classe operária urbana (Itinéraires ouvriers. Espaces et groupes sociaux à Turin au début du XXe siècle, Paris, 1987); ou ainda P.-A. Rosenthal ao tratar das modalidades do "êxodo rural" na França do século XIX (Les Sentiers invisibles. Espaces, familles et migrations dans la France du XIXe siècle, Paris, 1999), todos são exemplos da maneira como a abordagem microanalítica tornou possível uma releitura dos fenômenos maiores, muito além de um terreno de observação particular (observese, de passagem, que na maior parte dos exemplos que acabei de citar esta não se limita necessariamente a um perímetro "local").

Alguns quiseram, por vezes, ver na proposta micro-histórica a manifestação de um "retorno" do indivíduo na cena historiográfica da qual parecia ter desaparecido em benefício dos conjuntos sociais cujo estudo os historiadores privilegiavam desde duas ou três gerações. Tal afirmação é exagerada e também ambígua. O personagem heroico de Menocchio, expondo na frente do Tribunal do Santo Ofício, na segunda metade do século XVI, uma cosmologia materialista que mescla, segundo Carlo Ginzburg, um fundo de cultura euro-asiático muito antigo com elementos que esse semiletrado tomou de empréstimo e reelaborou a partir de uma série de leituras encontradas, é, sem nenhuma dúvida, excepcional. Não foi, todavia, essa excepcionalidade que reteve a atenção de Ginzburg, como não é ela que deveria reter a nossa, e sim a maneira como se constitui, com base em uma série de experiências heterogêneas - a persistência de um fundo muito antigo de cultura xamânica agrária, a divulgação, graças à imprensa, de um fluxo de textos antigos e modernos, a efetivação pela Igreja católica (e de forma mais geral pelas igrejas cristãs) de novas normas de ortodoxias etc. -, um espaço novo no qual experiências inéditas se tornam possíveis. Se aceitarmos esses termos, a atenção desloca-se do personagem Menocchio para aquilo que a experiência dele nos ensina sobre o mundo social onde vive. $\mathrm{O}$ indivíduo Menocchio torna-se então, por assim dizer, um marcador das reorganizações profundas vividas pela sua sociedade. Não um exemplo representativo no sentido estatístico da palavra, o que não teria muito sentido. Ao contrário do que anunciava Ginzburg em 1976, não é certo que existam nos arquivos cem ou mil Menocchios à espera do seu historiador e, se fosse o caso, eles apresentariam sem dúvida aspectos da experiência social diferentes daqueles que nos deu a conhecer $O$ queijo e os vermes. Nem por isso essa lição deixa de ultrapassar o quadro limitado da experiência individual. $\mathrm{O}$ que a história do moleiro Menocchio ajuda a entender são as dimensões sociais dessa experiência.

Sem dúvida, foi Giovanni Levi, em seu livro L'Eredità immateriale, que resumiu melhor o que está em jogo do ponto de vista historiográfico na perspectiva aberta pela micro-história (Levi, 1985). Ao estudar o que se passa num lugar "onde não se passa nada" - um burgo piemontês entre a metade do século XVII e o início do século XVIII -, ele coletou 
sistematicamente nos arquivos "todos os acontecimentos biográficos de todos os habitantes de Santena que deixaram algum rastro documental". Ele o fez com a intenção de ressaltar, por trás da tendência geral mais visível - aquela mesma que privilegiava a abordagem macro -, as múltiplas estratégias sociais implementadas pelos diferentes atores em função da sua posição e dos seus respectivos recursos individuais, familiares, de grupo etc. É incontestável que,

no final, todas as estratégias pessoais e familiares tendem talvez a $[. .$.$] fundir-se no relativo equilíbrio que resulta delas$ [a tendência geral que evoquei acima]. Mas a participação de cada um na história geral, na formação e na modificação das estruturas importantes da realidade social não pode ser avaliada unicamente com base em resultados tangíveis: no decorrer da vida de cada um, de maneira cíclica, nascem problemas, incertezas, escolhas, uma política da vida cotidiana cujo cerne é a utilização estratégica das regras sociais.

O termo "estratégia" não deve, porém, enganarnos. A ideia não significa aqui entender os atores sociais do passado como capazes de comandar de forma soberana seu destino, o que equivaleria a aplicar ao passado concepções de uma ideologia contemporânea que acredito ser, entretanto, profundamente falaciosa. O problema tampouco é aquele, metafísico, da liberdade humana para o qual os historiadores não têm, receio eu, nenhuma resposta substancial a fornecer. Ele é, mais simples e concretamente, o seguinte: como nós mesmos hoje, os atores do passado dispunham de certo número de recursos, cuja natureza e volume variavam e eram submetidos a pressões igualmente desiguais no seio de uma configuração social dada. A partir destes, eles deviam orientar-se no mundo social, em primeiro lugar para sobreviver, eventualmente para reforçar sua situação, seu estatuto, seus valores, suas crenças etc. Eles eram levados a efetuar escolhas entre um número limitado de possibilidades, em função da posição que ocupavam no mundo social e também a partir da representação do mundo social que lhes era accessível lá onde estavam. Eles não eram, então, "livres" para fazer o que quisessem, mas certamente tinham o senti- mento de se verem constantemente confrontados com alternativas: na escolha de uma aliança matrimonial ou na afirmação de uma solidariedade religiosa, num comportamento econômico, nas suas relações com as instituições. Novamente, considero que foi Levi quem foi mais longe na compreensão dessas estratégias modestas, minúsculas, ao introduzir, na análise das estratégias familiares camponesas desenvolvidas em volta do mercado da terra no Piemonte do século XVI, noções como as de incerteza, racionalidade limitada, fracasso (Levi, 1985).

Mediante o estudo intensivo e aproximado de configurações e processos sociais, a abordagem microhistórica assume, portanto, a tarefa de compreender como essas configurações se constituem e convivem (esse já era o problema colocado pelo sociólogo Norbert Elias a propósito da sociedade cortesã e, para além dela, de toda formação social). Ela procura também entender a maneira como movimentos ou transformações coletivos são possíveis, mas não a partir desses movimentos em si e da capacidade autorrealizadora que se lhes imputa, e sim da parte que cada ator toma neles (não podemos deixar de evocar a esse respeito a exposição da extraordinária intuição histórica de Tolstoi em Guerra e Paz, em que o destino da guerra e, mais amplamente, do enfrentamento entre potências é apreendido a partir da multiplicidade e do intricamento dos comportamentos individuais). Na história social, fenômenos de maior relevância, como a urbanização ou a industrialização, ou as formas de mobilidade social e também o ingresso na cultura escrita ou no espaço da política da massa não são mais abordados por mensurações globais, as dos fluxos advindos entre dois momentos sucessivos do tempo. Eles são reexaminados com base nos deslocamentos minúsculos, às vezes contraditórios, em todo caso diversificados, dos atores, sejam eles indivíduos ou grupos restritos. Migrar do campo e de uma atividade essencialmente agrária para a cidade e a gama de empregos que ela propõe deixam de ser percebidos como um processo inelutável e linear a partir do momento em que nos interrogamos sobre as razões dos atores sociais e principalmente sobre as formas concretas de suas escolhas. O que foi durante 
muito tempo chamado na França de "êxodo rural", isto é, a transferência maciça e tardia de uma população rural para as cidades a partir da segunda metade do século XIX, não é mais analisado unicamente como uma atração magnética que supostamente exerceria a cidade grande-e particularmente Paris -, mas mediante uma reorganização do conjunto das percepções locais do espaço social, desde o mais próximo até o mais longínquo. Foram essas percepções que deram início a trajetórias das quais se é finalmente possível dar conta a partir do seu ponto de partida e não mais do destino que se lhes atribuía tradicionalmente (Rosental, 1999).

Parece-me que a lição pode ser, a partir daí, generalizada a toda uma gama de realidades sóciohistóricas que tendemos, com demasiada frequência, a ler nos termos que elas mesmas nos sugerem. Citarei apenas um exemplo que tive frequentemente a oportunidade de desenvolver e do qual tirarei aqui apenas o essencial, o da construção do Estado moderno na Europa, desde a metade da Idade Média. É um modelo que, a partir da Europa e segundo modalidades diversas, se disseminou de forma muito ampla no mundo (apesar de sabermos que existiram construções estatais não europeias muito anteriores). Esse fenômeno da maior importância foi acompanhado muito precocemente por um conjunto de comentários teológicos, filosóficos, históricos cujo objetivo essencial era dar fundamentos à legitimidade desse modelo e, ao mesmo tempo, à sua irrefutabilidade. Mesmo quando o comentário queria ser crítico, como no caso das ciências sociais ou da filosofia política na época contemporânea, permaneceu como que fascinado pela afirmação global do Estado e das formas de poder que lhe são associadas. Tal constatação pode ser verificada de forma toda especial num país como a França, onde a afirmação do Estado é antiga e desempenhou papel determinante na construção nacional assim como na imagem identitária que a nação produziu de si mesma e se contempla prazerosamente. Todavia, de forma mais geral, ambiciosas elaborações históricas - de Marx a Max Weber, de Elias a Kantorowicz, para citar apenas algumas das mais notáveis - propuseram ler na história do Estado a realização de um tipo de programa já inscrito no coração do mundo social. Elas têm em comum o fato de aceitar como evidente a existência de um macrofenômeno cuja eficácia constituiria uma evidência - embora conviesse, sem dúvida, nuançar esse juízo no caso de Elias. O que era antigamente atribuído à Providência divina, à majestade do soberano, à virtude de um grande personagem aparece hoje de forma mais consensual como pertencendo à lógica de grandes arranjos anônimos que são, por isso mesmo, ainda mais incoercíveis.

Seria absurdo desconhecer a importância decisiva de uma realidade como a do Estado moderno. No entanto, a abordagem que permite a observação em várias escalas diferenciadas pode sugerir uma compreensão bem diferente. Visto de Paris, de Versalhes, de Berlim ou de Turim, o Estado moderno apresenta-se como uma vasta arquitetura centralizada cujas formas se ramificam ao infinito até penetrar no mais profundo da sociedade que ele enquadra e ambiciona assumir por completo. Tal é, ao menos, a imagem que ele quer dar de si mesmo. Os historiadores sabem muito bem que a realidade é um pouco mais complicada, um pouco menos harmoniosa. As instituições superpõem-se; elas entram frequentemente em concorrência, elas opõem-se às vezes umas às outras. Umas são apenas conservadas, enquanto outras estão em pleno desenvolvimento. Esse era um fato comum nas sociedades de Antigo Regime, mas ele está também presente nas sociedades modernas. Isso não impede que os historiadores continuem com a tentação de levar em consideração o conjunto das manifestações do Estado como se estivessem em presença de um processo único, contínuo, homogêneo do qual se poderiam tomar medidas globais mediante $o$ número dos agentes do Estado (oficiais, funcionários), as retiradas que ele impõe (impostos), o arsenal de normas que ele elabora ou, mais dificilmente, mediante a eficácia que se lhe atribui. Em todas essas operações, aparece como evidência a existência de uma lógica comum que unificaria o conjunto das manifestações do Estado e garantiria a tendência de melhoria das suas performances.

Porém, se renunciarmos a esse ponto de vista central, que é precisamente aquele com base no qual 
foi elaborado o projeto estatal (e também o conjunto de argumentos ideológicos que o legitimava), se modificarmos a escala de observação, as realidades começam a aparecer de forma bem diferente. Apanhado nas suas mais finas ramificações, o Estado moderno não é mais aquela mecânica imperiosa e unificadora: ele precisa aceitar negociações com o mundo social para poder ser reconhecido, como o mostraram, no caso da Europa, os trabalhos de Levi (1985), de Raggio (1990) e outros ou como o demonstram as pesquisas sobre os mundos colonizados pela Europa, nos quais ele se esforçou em impor suas concepções do mundo social. Para afirmar a existência de princípios, de regras de direito, é preciso compor com os usos e as formas de gestão tradicionais, como, por exemplo, na questão judiciária. Submetidos a novas coações, os atores sociais desenvolvem táticas para contorná-las ou evitá-las (elas são familiares, sob outro sistema de coações, aos sociólogos do trabalho industrial contemporâneo). Isso não equivaler a dizer que o Estado não tem existência nesse nível, o que seria absurdo. Mas que ele não existe nas formas que mais lhe agradam e que existe, sim, ao preço de tornar-se outra coisa.

Ainda assim, é por demais simples reduzir a questão a uma oposição esquemática entre o centro e suas periferias. Entre esses dois polos interpõe-se toda uma série de níveis intermediários. Os Estados do Antigo Regime, na Europa e nas extensões europeias pelo mundo, não eram capazes de assegurar suas funções essenciais a não ser delegando-as total ou parcialmente, compartilhando-as com linhagens aristocráticas para as funções de comando, administração e justiça ou com poderosos financistas para a cobrança do imposto e das taxas. Mesmo que não resistam sempre à privatização de parte de suas prerrogativas (nesse sentido, o movimento que partiu dos Estados Unidos se tornou poderoso no seio da Comunidade Europeia hoje), os Estados contemporâneos estão certamente mais atentos ao exercício de suas responsabilidades. Isso posto, quem não vê que na elaboração das decisões, na sua implementação assim como na execução das tarefas diárias de gestão, eles associam várias instâncias que se situam em diferentes níveis de competência e de conhecimento, sendo, portanto todos eles protagonistas de uma negociação? É demasiado fácil falar da tradição jacobina da administração francesa a qual, segundo Alexis de Tocqueville, ligaria o Antigo Regime aos regimes oriundos da Revolução e constituiria um dos caracteres originais da experiência francesa. A observação procede se compararmos esta última na longa duração com as da Grã-Bretanha, dos Estados Unidos ou do mundo alemão. Mas esquecemos assim que a construção pós-revolucionária na França foi objeto de uma longa negociação entre o governo central e a administração territorial que servia de intermediário aos interesses locais (Gremion, 1976; Verdier, 1999) pela mediação dos préfets. ${ }^{*}$

Não se trata aqui, mais uma vez, de negar a importância maciça de um fenômeno sócio-histórico como o da afirmação do Estado, mas, ao contrário, de aprender a olhá-lo e a compreendê-lo de outra maneira. Costuma-se com demasiada frequência considerá-lo um processo irresistível e até uma conclusão histórica (era assim que o representavam a historiografia e a filosofia política alemã no século XIX, assim como a ideologia dos regimes totalitários do século XX). Podemos tentar entender a maneira como a fórmula estatal ganhou crédito e foi também parcialmente retrabalhada, reformulada pelo jogo das práticas sociais que ela tinha por ambição enquadrar.

Dessa constatação podemos retirar duas indicações provisórias. A primeira sugere que os atores sociais - os do passado que os historiadores estudam e os do presente - sejam recolocados no coração dos processos sociais e que tentemos compreender a maneira pela qual eles intervêm na produção desses processos. A segunda, ilustrada pelo esboço bastante sucinto que acabei de fazer sobre a construção do Estado moderno, sugere que o meio de compreender esses processos em sua maior complexidade é apreendê-los em diversos

* Na França, os préfets são os representantes do governo central em cada um dos départements (subdivisões administrativas do país criadas durante a Revolução para substituir as antigas províncias) (N.doT.). 
níveis. O significado histórico e social do Estado não se situa unicamente no nível macro, tampouco somente no nível micro. Situa-se em todos os níveis em que pode ser identificada a implementação do processo estatizante. Cada um propõe, para o Estado, uma imagem diferente, e esta não se superpõe às imagens que podem ser constituídas em outros níveis. Nesse sentido, fazer uso de escalas de observação significa levar em consideração formas de descontinuidade presentes no mundo social efetivo. Toda realidade histórica maior, como é o caso do Estado, assume com certeza sua forma e seu sentido numa pluralidade de mundos sociais.

O que precede sugere evidentemente que se relativize a oposição tradicional entre abordagem micro e abordagem macroanalítica. Essa oposição tinha frequentemente por base a ideia implícita de que a cada uma delas correspondia, por direito, uma hierarquia de importância das realidades estudadas. Para as abordagens globais, os desafios maiores, os grandes processos, as evoluções profundas ou, retomando a célebre fórmula de Marx, a história que os homens fazem sem saber. Para as abordagens micro, o detalhe insignificante da vida cotidiana, os horizontes estreitos da "pequena história", a anedota sem importância: estas luzes vivas "que furam a noite sem iluminá-la", como dizia Braudel.

O modelo analítico que acabei de esboçar convida a pensar que é em todos os níveis, desde o mais local até o mais global, que os processos sócio-históricos são gravados, não apenas por causa dos efeitos que produzem, mas porque não podem ser compreendidos a não ser que os consideremos, de forma não linear, como a resultante de uma multiplicidade de determinações, de projetos, de obrigações, de estratégias e de táticas individuais e coletivas. Somente essa multiplicidade desordenada e em parte contraditória nos permite dar conta da complexidade das transformações do mundo social. Um fato destaca-se, afinal: as formas mais interessantes, aos meus olhos, da nova "história global" são aquelas que, longe de partir da ideia de que os processos sociais maiores são naturalmente globais, procuram dar conta das circulações que tor- naram possíveis a globalização, das conexões e das encruzilhadas, das formas de hibridação que estão na sua base e que são as únicas a torná-las compreensíveis. ${ }^{3}$ Quem não vê que esse tipo de análise convida o historiador a multiplicar as escalas de observação para poder reatravessar o conjunto dos níveis da produção do social?

Chego aqui para concluir a questão anunciada no título e que retive para esta exposição: que ajuda nos dão as variações de escala para pensar um mundo em vias de globalização - ou, falando de forma mais brutal, será que nos ajudam a pensar o que quer que seja? Essa última formulação permite adivinhar que minha resposta é positiva. Mas o que afirmo principalmente é que a relação pode ser invertida, e que é precisamente porque estamos confrontados a um fenômeno, a um conjunto de fenômenos - geralmente classificado como "globalização" ou "mundialização" - que a atenção dos historiadores, e mais amplamente dos especialistas em ciências sociais, se debruçou recentemente sobre a falta de articulação entre os diferentes níveis em que se pode apreender a organização e o funcionamento do mundo social.

Com certeza, minha intenção não é aqui lançar dúvidas sobre a realidade dos processos que contribuem hoje para unificar as sociedades humanas. Dos fluxos de informação aos fluxos financeiros, da circulação dos homens à dos bens materiais e culturais, das produções ao consumo, nosso espaço encolheu e as durações reduziram-se. Sem dúvida, os historiadores não cessaram de lembrar que essa mundialização não é a primeira. Serge Gruzinski, assim como outros, insistiram com propriedade sobre o fato de que a compreensão da "primeira" (a primeira?) mundialização, a das monarquias europeias - e, particularmente a da monarquia católica ibérica -, podia permitir-nos decifrar os processos que estão agindo sob os nossos olhos, não no sentido de que essa compreensão nos proporia um precedente e menos ainda improváveis

\footnotetext{
${ }^{3}$ Ver, por exemplo, o número especial das Annales, 1, 2001,
} "Une histoire à l'échelle globale". 
origens, mas no sentido de que ela nos permite refletir, mediante um jogo de diferenças e de desníveis, sobre a maneira como se articulam entre si no tempo os conjuntos sociais heterogêneos.

Apesar disso, permanecemos na maior parte do tempo desarmados ante esta transformação do mundo que parece impor-se, na nossa vista em tempo real, uma transformação que a internet, da qual nos tornamos todos usuários entusiastas ou forçados, retrata sem dúvida da forma mais evidente hoje. Talvez seja nesse ponto que uma reflexão sobre as escalas pode ajudar-nos a retomar certo domínio sobre esses processos que nos ultrapassam. Aceitamos, com demasiada frequência, representá-los para nós mesmos como fatalidades inelutáveis, segundo os velhos esquemas evolucionistas do século XIX. Essas convicções, que são também construções ideológicas, visam em primeiro lugar racionalizar o que existe - o que é também uma forma de legitimá-lo. Tenho claro que o que pensam os historiadores não tem provavelmente muito peso perante a potência das forças em jogo. Mas continuo convicto de que do lugar que eles ocupam, pelas suas análises e pela capacidade crítica que podem transmitir aos seus estudantes, eles têm capacidade de relembrar essa verdade simples, essencial, mas tão esquecida: as grandes transformações que alteram profundamente a face da Terra não existem em nenhuma parte a não ser pela ação de atores que, na lógica dos contextos peculiares da sua experiência social, se esforçam em garantir para si um lugar, isoladamente e/ou com outros. Cabe à História e às ciências sociais reconhecer esses lugares e as lógicas de ação que deles fazem parte.

\section{Referências bibliográficas}

BRAUDEL, Fernand. Ecrits sur l'histoire. Paris: Flammarion, 1969.

La longue durée. Annales ESC, 1958 (depois reproduzido em Ecrits sur l'histoire).

La Méditerranée et le monde méditerranéen à l'époque de Philippe II. Paris, 1949; segunda edição remanejada, Paris: Armand Colin, 1966.
BRAUDEL, Fernand; LABROUSSE, Ernest (Ed.). Histoire économique et sociale de la France. 8 vols. Paris: Presses Universitaires de France, 1970-1982.

FURET, François. L'histoire quantitative et la construction du fait historique. Annales ESC, v. XXVI p. 63-75, 1971.

GINZBURG, Carlo. Microstoria: due o tre cose che so di le. Quaderni Storici, v. 86, p. 511-539, 1994.

. Miti, emblemi, spie. Morfologia e storia. Turin: Einaudi, 1986. p. 158-209.

. Spie. Radici di un paradigma indiziario (de 1979). In: GINZBURG, Carlo; PONI, Carlo. Il nome e il come. Mercato storiografico e scambio disuguale. Quaderni Storici, v. 40, p. 181190, 1979.

GREMION, Pierre. Le pouvoir périphérique: bureaucrates et notables dans le système politique français. Paris: Éd. du Seuil, 1976.

GRENDI, Edoardo. Micro-analisi e storia sociale. Quaderni Storici, v. 35, p. 506-520, 1977.

LABROUSSE, Ernest. Esquisse du mouvement des prix et des revenus dans la France du XVIII ${ }^{e}$ siècle. Paris: 1933.

LEVI, Giovanni. L'Eredità immateriale: la carriera di un esorcista nel Piemonte del Seicento. Turin: Einaudi, 1985.

MOMIGLIANO, Arnaldo . Problèmes d'historiographie ancienne et moderne. Paris: Gallimard, 1983.

RAGGIO, Osvaldo. Faide e parentele: lo Stato Genovese visto dalla Fontanabuona. Turin: Einaudi, 1990.

ROSENTAL, Paul André. Les sentiers invisibles: espace, familles et migrations dans la France du 19e siècle. Paris: Editions de 1'Ecole des hautes études en sciences sociales, 1999.

SIMIAND, François. Méthode historique et science sociale. Revue de Synthèse historique, 1903, t. VI, n. 16, p. 1-22; 1903, t. VI, n. 17, p. 129-157.

VERDIER, Nicolas. Penser le territoire au XIXe siècle. École de Hautes Études en Sciences Sociales, 1999.

JACQUES REVEL é diretor de pesquisas na École des Hautes Études en Sciences Sociales, em Paris, onde desenvolve pesquisas sobre historiografia contemporânea. Publicações recentes no Brasil: Proposições: ensaios de história e historiografia (Rio de Janeiro: EDUERJ, 2009); História e historiografia: exercícios críticos (Curitiba: Editora da UFPR, 2010).E-mail: revel@ehess.fr

Recebido em maio de 2010 Aprovado em junho de 2010 
Jacques Revel

Micro-história, macro-história: o que as variações de escala ajudam a pensar em um mundo globalizado

Os cientistas sociais opõem atualmente a micro e a macro análise em termos de tópicos, desafios e estratégias da pesquisa. Nas décadas passadas, historiadores também debateram e compararam as vantagens da micro-história com versões diferentes da história do macro, a transnacional ou a global. Este ensaio sugere como alternativa colocar a atenção sobre a importância do princípio de variação das escalas da observação, em termos heurísticos e críticos. Esboça um modelo analítico que convida a pensar que é em todos os níveis, desde o mais local até o mais global, que os processos sóciohistóricos são gravados. Só podem ser compreendidos, portanto, como resultantes de uma multiplicidade de determinações, projetos, obrigações, estratégias e táticas individuais e coletivas.

Palavras-chave: teorias da história; micro-história; globalização

Micro history, macro history: what the variations in scale help to think in a globalized world

Nowadays, social scientists oppose micro and macro analysis in terms of topics, challenges and research strategies. In past decades, historians also debated and compared the advantages of micro history, with different versions of the history of the macro, transnational or global. This essay suggests, as an alternative, paying attention to the importance of the variation principle in the scales of observation, in critical and heuristic terms. It sketches an analytic model that leads one to think that it is on every level, from the most local to the most global, that socio-historical processes are preserved. Therefore, they can only be understood as the result of a multiplicity of individual and collective determinations, projects, obligations, strategies and tactics.

Key words: theories of history; micro history; globalization.

Micro historia, macro historia: lo que las variaciones de escala ayudan a pensar en un mundo globalizado

Los cientificos sociales actualmente oponen el micro y el macro análisis en términos de tópicos, desafios y estrategias de datos. En las décadas pasadas, historiadores también discutieron y compararon las ventajas de la micro historia con diferentes versiones de la historia del macro, la transnacional o la global. Este ensayo sugiere como alternativa colocar la atención sobre la importancia del principio de variación de las escalas de la observación, en términos heurísticos y críticos. Esboza un modelo analítico que nos lleva a pensar que es en todos los niveles, desde el más local hasta el más global, que los procesos socios históricos son grabados. Sólo pueden ser comprendidos, por lo tanto, como resultados de una multiplicidad de determinaciones, proyectos, obligaciones, estrategias y tácticas individuales y colectivas.

Palabras clave: teorías de la historia; micro historia; globalización 